\title{
Implementasi Model Pembelajaran REPICPRO (Resume, Picture, Problem Based Learning) Mata Pelajaran IPS Kelas VII SMP Pada Materi Kelangkaan Dan Kebutuhan Manusia
}

\author{
Efa Wahyu Prastyaningtyas ${ }^{1}$, Widi Wulansari ${ }^{2}$ \\ efawahyu@unpkediri.ac.id'; widiwulansari@unpkediri.ac.id² \\ Universitas Nusantara PGRI Kediri1,2
}

\begin{abstract}
The aim of this quasi experimental study is to find out how the implementation of REPICPRO model on social sciences subject of seventh grade students at Junior High School to scarcity and human needs materials. One group pre-test pos-ttest design was used in this research. The data analyzes technique used Paired t-test. The result showed that there was a difference score between pre-test and post-test with t- score of 5,461 and significance of 0,0001. The average of pre- test score was 66 and post- test score was 77,33 . Thus, the result of the study showed that student learning outcomes was increased, so that the implemetation of the REPICPRO method had a positive and significant effect on the learning outcomes of seventh grade students to scarcity and human needs materials.
\end{abstract}

Keywords: Learning models, Resumes, Pictures, Problem based learning

Abstrak

Tujuan penelitian eksperiemen semu ini untuk mengetahui bagaimana implementasi model pembelajaran REPICPRO mata pelajaran IPS Kelas VII SMP pada materi kelangkaan dan kebutuhan manusia. One Group Pretest Posttest Design merupaka metode yang digunakan. Tehnik analisis data yang digunakan uji statistika Paired $t$-test. Hasil penelitian menunjukkan adanya perbedaan antara nilai pre test dan pos test dengan nilai t sebesar 5,461 dan signifikansi 0,0001 . Rata-rata nilai pre test sebesar 66 dan nilai pos test 77,33. Dengan demikian hasil penelitian menunjukkan adanya peningkatan hasil belajar siswa sehingga implementasi metode pembelajara Repicpro berpengaruh positif dan signifikan terhadap hasil belajar siswa kelas VII pada materi kelangkaan dan kebutuhan manusia.

Kata kunci: Model pembelajaran, Resume, Picture, Problem based learning.

\section{PENDAHULUAN}

Keberhasilan dalam proses pembelajaran tidak luput dari peran seorang guru, karena guru bisa berperan sebagai pemberi petunjuk tentang cara belajar yang efektif, membimbing sekaligus mengawasi pelaksanaan kegiatan pembelajaran sehingga tercapai tujuan pembelajaran dengan maksimal (Kirom, 2017). Pada kurikulum 2013 saat ini menuntut guru tidak lagi berperan sebagai teacher center yang menjadi penguasa kelas melainkan sudah beralih pada students center(Dewi, 2016). Guru juga dituntut untuk menjadi multi peran sebagai motivator dan fasilitator yang dapat memengaruhi proses belajar tanpa mengabaikan model pembelajaran yang diterapkan dalam kegiatan belajar tersebut (Agustianingsih, 2014)

Proses pembelajaran hendaknya dilakukan secarainteraktif, inspiratif, menyenangkan, menantang, memotivasi siswa supaya berpartisipasi aktif, selain itu memberikan wadah bagi siswa untuk mengembangkan prakarsa, kreativitas, dan kemandirian sesuai dengan bakat, minat, dan perkembangan fisik serta psikologis siswa(Sofyan \& Komariah, 2016). Dan untuk mewujudkan tercapainya kompetensi yang diinginkan makaguru harus membuat perencanaan pembelajaran secara efektif dan efisien. 


\section{Efektor, Volume 7 Issue 1, 2020, Pages 35-41}

Efa Wahyu Prastyaningtyas, Widi Wulansari

Guru merencanakan pembelajaran tentang model pembelajaran yang akan diterapkan, mengingat tidak semua model pembelajaran dapat diterapkan pada semua mata pelajaran, dan bila guru salah memilih metode pembelajaran akan berakibat pada prestasi belajar siswa tidak tercapai sesuai dengan yang diharapkan (Istiatutik, 2017). Model pembelajaran tersebut bisa berupa resume, meskipun terlihat sederhana metode ini sangat membantu meningkatkan pengetahuan siswa dalam mempersiapkan materi yang akan dibahas. Tujuannya memudahkan siswa dalam kegiatan belajar mengajar serta menggali pemikiran siswa dalam menemukan permasalahan-permasalahan yang mereka temukan dalam proses resume serta bisa menjadi bahan diskusi di kelas (Dewi, 2016).

Sementara model pembelajaran picture and picture disampaikan guru ketika akan membahas tentang materi kelangkaan dan kebutuhan manusia dengan menyajikan gambar dan memberikan pertanyaan kepada siswa dengan tujuan agar siswa lebih aktif, kreatif dan inovatif dalam proses pembelajaran. Hal itu didukung dengan penelitian (Zuhdi, 2014; Suyana, 2018) yaitu dengan menggunakan model pembelajaran picture and picture siswa memperoleh pengalaman aktif dan menyenangkan dalam belajar serta dapat meningkatkan hasil belajar siswa.

Fokus pembelajaran PBL ada pada siswa bukan pada gurunya. Langkah pembelajaran model ini dimulai dengan memberikan "masalah" yang bersumber dari keadaan nyata yang ditemuai oleh siswa,kemudian siswa secara berkelompok melakukan identifikasi masalah. Siswa mencari dan mempelajari sendiri materi yang berkaitan dengan masalah tersebut kemudian melaporkan solusi dari masalah berdasarkan hasil belajar yang mereka lakukan (Rahmat, 2017; Ika Latifatun Nikmah, 2018; Isrokijah, 2015).

Mata pelajaran IPS merupakan mata pelajaran yang diperoleh siswa untuk jenjang SD dan SMP, dimana kajian ilmu yang diajarkan terdiri dari ekonomi, sejarah dan geografi yang dikemas dalam satu mapel yaitu IPS terpadu baik di jenjang SD maupun SMP. Pada penelitian ini lebih menitik beratkan pada mata pelajaran IPS terpadu SMP kelas VII dengan kajian ilmu ekonomi pada materi kelangkaan dan kebutuhan manusia

Hasil observasi awal peneliti pada mata pelajaran IPS kelas VII SMPN 2 Prambon menunjukkan bahwa model pembelajaran masih secara konvensional dengan menggunakan metode ceramah, tanya jawab dan penugasan sehingga membuat siswa menjadi kurang aktif dan membosankan. Penerapan metode konvensional oleh guru berdampak pada kurang maksimalnya dalam peningkatan hasil belajar siswa, hal itu dapat dilihat dari hasil PTS (Penilaian Tengah Semester) di semester I menunjukkan 64\% siswa nilainya masih di bawah KKM sedangkan hasil pre test sebelum dilakukan penelitian pada materi aktivitas manusia dalam memenuhi kebutuhan diketahui ada $75 \%$ siswa yang mendapat nilai di bawah KKM.

Model pembelajaran yang dipilih guna meningkatkan prestasi belajar siswa pada materi aktivitas manusia dalam memenuhi kebutuhan adalah Kolaborasi penggunaan metode resume, picture and picture, dan Problem Based Learning atau disingkat dengan istilah REPICPRO. Dimana tujuan dari penggunaan metode REPICPRO adalah membantu siswa untuk mengerti dan memahami materi aktivitas manusia dalam memenuhi kebutuhan secara menyenangkan, dan contextual. 


\section{METODE PENELITIAN}

Metode yang digunakan dalam penelitian ini adalah eksperimen semudengan tujuan untuk mengetahui suatu gejala atau pengaruh yang timbul sebagai akibat dari adanya suatu perlakuan tertentu. Desain yang digunakan adalah One Group Pretest Posttest Design.

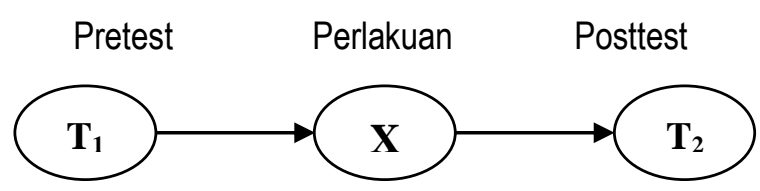

Gambar 1. Desain Penelitian

Penelitian ini dilakukan di semester ganjil tahun akademik 2019/2020 dan dilaksanakan pada bulan Oktobersampai Desember2019. Sampel dalam penelitian ini adalah satu kelas VII di SMP Negeri 2 Prambon sebanyak 30 siswa. Teknik pengumpulan data yang digunakan dalam penelitian ini adalah pretest dan posttest. Pretest digunakan untuk mengetahui kemampuan awal siswa tentang pengetahuan kelangkaan dan kebutuhan manusia. Posttest digunakan untuk mengetahui kemampuan akhir siswa tentang pengetahuan kelangkaan dan kebutuhan manusia setelah mendapat metode pembelajaran REPICPRO. Instrumen yang digunakan adalah soal pretest dan posttest.

Teknik analisis data yang digunakan adalah statistika parametrik dengan Paired t-test. Agar uji hipotesis dapat dilakukan maka terlebih dahulu dilakukan uji prasyarat analisis, yang meliputi uji normalitas dan uji homogenitas. Uji normalitas dimaksudkan untuk mengetahui apakah sampel yang diambil dalam penelitian ini berasal dari populasi yang berdistribusi normal atau tidak. Untuk uji normalitas dilakukan dengan uji KolmogorovSmirnov sedangkan uji homogenitas data digunakan uji Levene.

\section{HASIL DAN PEMBAHASAN}

\section{Langkah-langkah Implementasi Metode Pembelajaran REPICPRO}

Proses penelitian melalui 2 tahap pertemuan, yaitu pertemuan 1 membahas tentang pengertian kelangkaan, penyebab terjadinya kelangkaan dan cara untuk mengatasi kelangkaan. Pertemuan 2 Pengertian kebutuhan, Jenis-jenis kebutuhan manusia dan Alat pemuas kebutuhan.

Tabel 1. Langkah-langkah Implementasi REPICPRO

\begin{tabular}{ll}
\hline No & Langkah-langkah Pembelajaran \\
\hline 1. & $\begin{array}{l}\text { Pertemuan sebelumnya siswa diberi } \\
\text { tugas oleh guru untuk meresume materi } \\
\text { tentang kelangkaan. }\end{array}$ \\
\hline $2 . \quad$ & $\begin{array}{l}\text { Siswa duduk berdasarkan kelompok } \\
\text { yang sudah ditentukan oleh guru }\end{array}$ \\
\hline $3 . \quad$ & $\begin{array}{l}\text { Guru menjelaskan tujuan pembelajaran, } \\
\text { guru menyampaikan materi dengan } \\
\text { menyajikan gambar kelangkaan sebagai } \\
\text { masalah ekonomi manusia }\end{array}$ \\
\hline 4. & $\begin{array}{l}\text { Siswa mengamati gambar kelangkaan } \\
\text { sebagai masalah ekonomi manusia. }\end{array}$
\end{tabular}

Gambar Soal

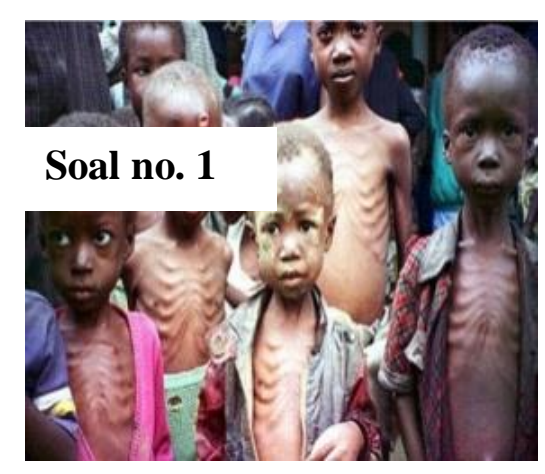


Efektor, Volume 7 Issue 1, 2020, Pages 35-41

Efa Wahyu Prastyaningtyas, Widi Wulansari

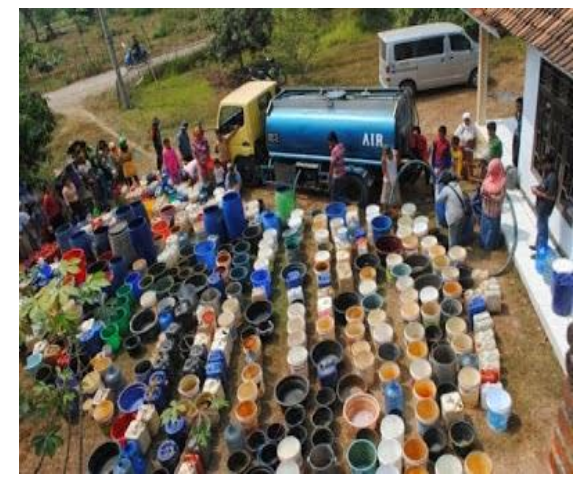

Soal no. 2

\begin{tabular}{lll}
\hline 5 & Siswa menayakan atau & 1) Peristiwa apa yang terjadi pada gambar tersebut? \\
mempertanyakan tentang kelangkaan & 2) Apa yang kalian pikirkan ketika melihat gambar tersebut? \\
sebagai masalah ekonomi manusia. & 3) Apa yang menyebabkan terjadinya peristiwa seperti pada gambar \\
Guru mengarahkan pada pertanyaan- & tersebut? \\
pertanyan yang mengarah pada materi. & 4) Bagaimana cara mengatasi hal tersebut?
\end{tabular}

6 Siswa melakukan kegiatan diskusi bersama kelompok untuk menganalisis gambar kelangkaan sebagai permasalahan ekonomi manusia dengan mencari informasi baik dari hasil resume maupun buku.

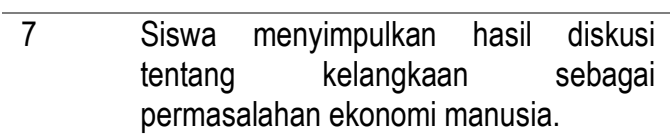

8 Siswa menyajikan hasil analisis gambar dengan mempresentasikannya di depan kelas yang diwakili oleh salah satu anggota kelompok dan anggota kelompok yang lain memberikan tanggapan; untuk memotivasi siswa agar mau bertanya atau menyampaikan pendapatnya guru bisa menggunakan reward (pujian atau tepuk tangan). Tugas guru disini adalah menghidupkan suasana kelas ketika diskusi.

9 Siswa menyajikan hasil simpulan hasil diskusi masing-masing kelompok pada selembar kertas.
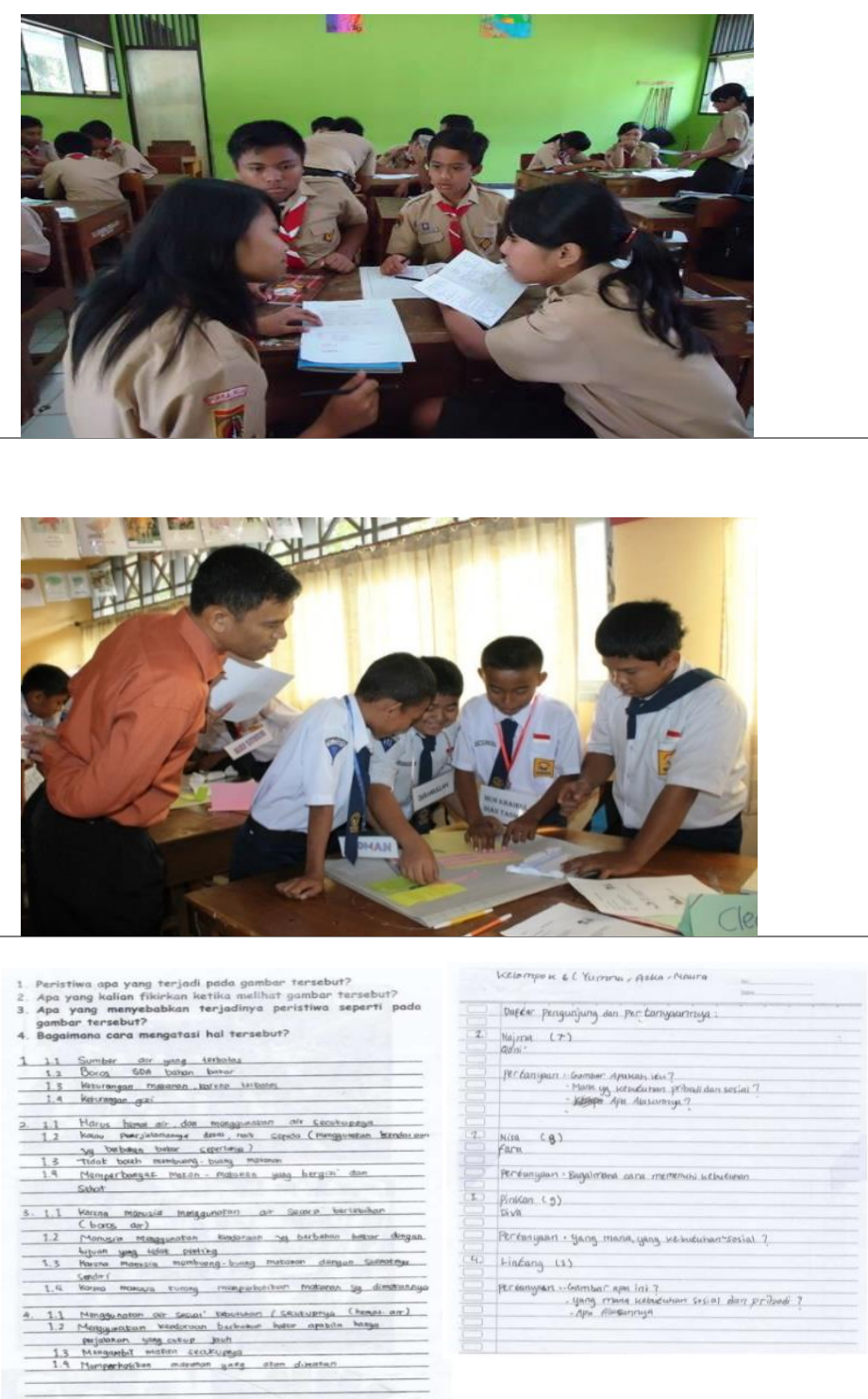
10 Penutup

11. Evaluasi
1. Guru memberikan komentar terhadap hasil pekerjaan siswa yang telah dipresentasikan, dan memberikan masukan yang membangun.

2. Guru memberikan penguatan pada materi yang disampaikan dalam pembelajaraan yang sedang berlangsung.

3. Guru memeriksa pekerjaan siswa yang sudah selesai dengan memberi paraf pada hasil pekerjaan (projek) yang sudah diselesaikan siswa dengan memberi nomer urut peringkat segai bentuk penilaian projek. Selanjutnya guru memberi rewards bagi kelompok yang kinerja dan kerjasamanya baik.

4. Dipertemuan selanjutnya siswa diberi tugas oleh guru untuk membuat resume materi jenis-jenis kebutuhan bersama kelompok.

- Pada pertemuan selanjutnya guru memberikan apersepsi materi yang telah disampaikan pada pertemuan sebelumnya, dengan memberikan pertanyaan kepada 1 atau 2 orang siswa.

- $\quad$ Guru mengamati aktifitas siswa (aktif dan pasif) ketika melakukan diskusi kelompok.

- Guru memantau hasil kegiatan belajar tentang kelangkaan kebutuhan sebagai masalah ekonomi, jika pengetahuan siswa terhadap materi masih kurang maka guru harus mengevaluasi kembali metode pembelajaran yang telah digunakan.

\section{Uji Pengaruh Metode Pembelajaran REPICPRO pada Mata Pelajaran IPS dengan Materi Kelangkaan dan Kebutuhan Manusia}

\section{Uji Asumsi}

Sebelum dilakukan uji Paired t-testmaka terlebih dahulu dilakukan uji asumsi yang meliputi uji normalitas dan homogenitas untuk nilai pretest dan posttest. Berikut hasil dari uji normalitas dan homogenitas dari nilai pretest dan posttest dengan jumlah sampel sebanyak 30 siswa.

Tabel 2. Hasil Uji Normalitas dan Homogenitas

\begin{tabular}{cccccc}
\hline \multirow{2}{*}{ Nilai } & \multicolumn{2}{c}{ Normalitas } & \multicolumn{2}{c}{ Homogenitas } & Hipotesis \\
& Nilai & Sig. & Nilai & Sig. & \\
\hline Pretest & 1,251 & 0,087 & 2,270 & 0,090 & Ho diterima \\
\hline Posttest & 0,917 & 0,369 & 0,233 & 0,873 & \\
(Sig $>0,05)$ \\
\hline
\end{tabular}

Berdasarkan tabel 2dapat disimpulkan bahwa sampel yang diambil memenuhi pengujian asumsi sehingga dapat dilakukan uji hipotesis dengan statistika parametrik yaitu Paired t-test.

\section{Pengujian Hipotesis}

Uji hipotesis dilakukan untuk melihat apakah ada ada perbedaan nilai pretest dan pottest siswa kelas VII pada mata pelajaran IPS dengan materi kelangkaan dan kebutuhan siswa melalui model pembelajaran REPICPRO. Berikut hasil uji hipotesis disajikan dalam tabel 3.

Tabel 3. Hasil Uji Hipotesis dengan Paired t-test

\begin{tabular}{|c|c|c|c|c|c|c|c|c|c|}
\hline & & \multicolumn{5}{|c|}{ Paired Differences } & \multirow[t]{3}{*}{$\mathrm{t}$} & \multirow[t]{3}{*}{ df } & \multirow{3}{*}{$\begin{array}{l}\text { Sig. (2- } \\
\text { tailed) }\end{array}$} \\
\hline & & \multirow[t]{2}{*}{ Mean } & \multirow[t]{2}{*}{$\begin{array}{c}\text { Std. } \\
\text { Deviation }\end{array}$} & \multirow[t]{2}{*}{$\begin{array}{l}\text { Std. Error } \\
\text { Mean }\end{array}$} & \multicolumn{2}{|c|}{$\begin{array}{l}\text { 95\% Confidence Interval } \\
\text { of the Difference }\end{array}$} & & & \\
\hline & & & & & Lower & Upper & & & \\
\hline Pair 1 & $\begin{array}{l}\text { Pretest - } \\
\text { Posttest }\end{array}$ & -11.333 & 11.366 & 2.075 & -15.578 & -7.089 & -5.461 & 29 & .000 \\
\hline
\end{tabular}

Berdasarkan tabel 3 dapat dilihat nilai sig sebesar 0,0001 sehingga dapat diartikan bahwa nilai sigkurang dari nilai alpha yg ditetapkan yaitu 0,05 . Kesimpulannya bahwa Ho ditolak dan Ha diterima. 
Efektor, Volume 7 Issue 1, 2020, Pages 35-41

Efa Wahyu Prastyaningtyas, Widi Wulansari

Tabel 4. Hasil Korelasi antara Nilai Pretest dan Posttest

\begin{tabular}{lcccc}
\hline & & N & Correlation & Sig. \\
\hline Pair 1 & Pretest \& Posttest & 30 & .549 & .002 \\
\hline
\end{tabular}

Hasil korelasi antara nilai pretest dan posttestdari tabel 4 menunjukkan adanya korelasi yang positif dan signifikan.

Tabel 5. Hasil Statistika Deskriptif

\begin{tabular}{lllccc}
\hline \multirow{2}{*}{ Pair 1 } & & Mean & N & Std. Deviation & Std. Error Mean \\
\cline { 2 - 6 } & Pretest & 66.00 & 30 & 12.205 & 2.228 \\
\cline { 2 - 6 } & Posttest & 77.33 & 30 & 11.725 & 2.141 \\
\hline
\end{tabular}

Hasil dari tabel 5 menunjukkan bahwa nilai posttest lebih tinggi daripada nilai pretest.Berdasarkan hasil uji hipotesis dapat disimpulkan bahwa ada perbedaan nilai pretest dan pottest siswa kelas VII pada mata pelajaran IPS dengan materi kelangkaan dan kebutuhan siswa melalui model pembelajaran REPICPRO serta nilai yang meningkat. Dengan demikian dapat diartikan bahwa implementasi model pembelajaran REPICPRO (Resume, Picture, Problem Based Learning) mata pelajaran IPS kelas VII SMP pada materi kelangkaan dan kebutuhan manusia memberikan hasil yang positif dan signifikan.

\section{SIMPULAN}

Implementasi metode resume, picture and picture, dan Problem Based Learning (REPICPRO) menjadikan siswa aktif dan kreatif untuk mengerti dan memahami materi aktivitas manusia dalam memenuhi kebutuhan secara menyenangkan, dan contextual. Hasil belajar siswa menunjukkan mengalami peningkatan yang signifikan sehingga implementasi metode pembelajaran REPICPRO mempunyai pengaruh yang positif.

\section{DAFTAR PUSTAKA}

Agustianingsih, E. R. (2014). Pengembangan Model Pembelajaran Berbasis Masalah Pokok Bahasan Jurnal Penyesuaian Kelas Xi Sma. Journal of Economic Education, 3(1).

Dewi, J. A. S. I. N. A. (2016). Implementasi model pembelajaran request ( resume, question, investigation, solution and presentation ) terhadap keterampilan metakognisi siswa smp dalam pembelajaran ipa. Pancaran, 5(4), 11-20.

Ika Latifatun Nikmah. (2018). the Implementation of Problem Based Learning To Improve Students' Understanding in Management of Laboratorium Subject. International Education \& Research Journal (IERJ), 10(2), 197-205. https://doi.org/10.15408/es.v10i2.7376

Isrokijah. (2015). Developing Problem-Based Learning (PBL) Worksheets for the Eight Grade Students at Junior High School. Language and Language Teaching Journal, 18(2), 99-106.

https://doi.org/10.24071/lt.2015.180203

Istiatutik, I. (2017). Penerapan Metode Problem Based Learning untuk Meningkatkan Hasil Belajar Pelajaran Ekonomi. Jurnal Pendidikan : Riset Dan Konseptual, 1(1), 45. https://doi.org/10.28926/riset_konseptual.v1i1.6

Kirom, A. (2017). Peran Guru Dan Peserta Didik Dalam Proses Pembelajaran Berbasis Multikultural. Al Murabbi, 3(1), 69-80. Retrieved from http://jurnal.yudharta.ac.id/v2/index.php/pai/article/view/893 
Rahmat, E. (2017). Penerapan Model Pembelajaran Problem Based Learning Untuk Meningkatkan Prestasi Belajar Ips. Jurnal Penelitian Pendidikan, 1(3), 206.

https://doi.org/10.23887/jisd.v1i3.11997

Sofyan, H., \& Komariah, K. (2016). Pembelajaran Problem Based Learning Dalam Implementasi Kurikulum 2013 Di Smk. Jurnal Pendidikan Vokasi, 6(3), 260. https://doi.org/10.21831/jpv.v6i3.11275

Suyana, A. P. A. S. W. N. (2018). Jurnal ADIMAS. ADIMAS, 30-36.

Zuhdi, D. Y. (2014). Penerapan Model Pembelajaran Picture and Picture Untuk Meningkat Hasil Belajar Pada Pembelajaran Tematik Di Sekolah Dasar. JPGSD, 2, 1-10. Retrieved from https://jurnalmahasiswa.unesa.ac.id/index.php/jurnal-penelitian-pgsd/article/view/10594/4182 